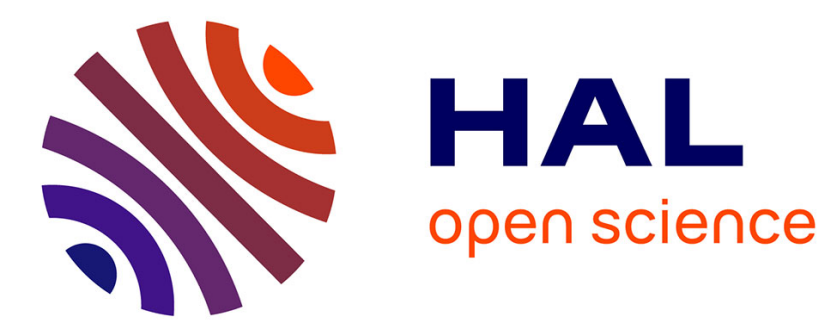

\title{
Testing for Asymmetries in the Preferences of the Euro-Area Monetary Policymaker
}

\author{
Alvaro Aguiar, Manuel M. F. Martins
}

\section{To cite this version:}

Alvaro Aguiar, Manuel M. F. Martins. Testing for Asymmetries in the Preferences of the Euro-Area Monetary Policymaker. Applied Economics, 2008, 40 (13), pp.1651-1667. 10.1080/00036840600870999 . hal-00582028

\section{HAL Id: hal-00582028 \\ https://hal.science/hal-00582028}

Submitted on 1 Apr 2011

HAL is a multi-disciplinary open access archive for the deposit and dissemination of scientific research documents, whether they are published or not. The documents may come from teaching and research institutions in France or abroad, or from public or private research centers.
L'archive ouverte pluridisciplinaire HAL, est destinée au dépôt et à la diffusion de documents scientifiques de niveau recherche, publiés ou non, émanant des établissements d'enseignement et de recherche français ou étrangers, des laboratoires publics ou privés. 


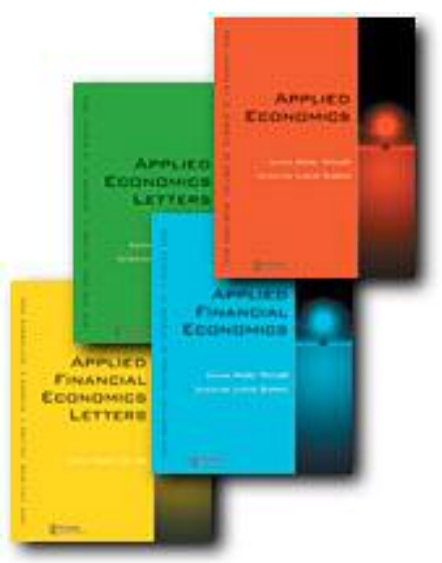

Testing for Asymmetries in the Preferences of the Euro-Area Monetary Policymaker

\begin{tabular}{|c|c|}
\hline Journal: & Applied Economics \\
\hline Manuscript ID: & APE-05-0695 \\
\hline Journal Selection: & Applied Economics \\
\hline $\begin{array}{r}\text { Date Submitted by the } \\
\text { Author: }\end{array}$ & 12-Dec-2005 \\
\hline JEL Code: & $\begin{array}{l}\text { C32 - Time-Series Models < C3 - Econometric Methods: } \\
\text { Multiple/Simultaneous Equation Models < C - Mathematical and } \\
\text { Quantitative Methods, E52 - Monetary Policy (Targets, Instruments, } \\
\text { and Effects) < E5 - Monetary Policy, Central Banking, and the } \\
\text { Supply of Money and Credit < E - Macroeconomics and Monetary } \\
\text { Economics, E58 - Central Banks and Their Policies < E5 - Monetary } \\
\text { Policy, Central Banking, and the Supply of Money and Credit < E - } \\
\text { Macroeconomics and Monetary Economics }\end{array}$ \\
\hline Keywords: & $\begin{array}{l}\text { Central Bank Preferences, Asymmetry, Euro Area, GMM, Optimal } \\
\text { Control }\end{array}$ \\
\hline
\end{tabular}




\title{
Testing for Asymmetries in the Preferences of the Euro-Area Monetary Policymaker
}

\section{Alvaro Aguiar and Manuel M. F. Martins}

CEMPRE*, Faculdade de Economia, Universidade do Porto

First version: July 2005

This version: November 2005

\begin{abstract}
This paper tests for asymmetries in the preferences of the Euro-Area monetary policymaker with 1995:I-2005:II data from the latest update of the ECB's Area-wide database. Following the relevant literature, we distinguish between three types of asymmetry: precautionary demand for expansions, precautionary demand for price stability and interest rate smoothing asymmetry. Based on the joint GMM estimation of the Euler equation of optimal policy and the AS-AD structure of the macroeconomy, we find evidence of precautionary demand for price stability in the preferences revealed by the monetary policymaker. This type of asymmetry is consistent with the ECB's definition of price stability and with the priority of credibility-building by a recently created monetary authority.
\end{abstract}

Keywords: Central Bank Preferences, Asymmetry, Euro Area, Optimal Control, GMM.

JEL classification: E52, E58, C32.

* CEMPRE - Centro de Estudos Macroeconómicos e Previsão - is a research centre supported by the Fundação para a Ciência e a Tecnologia, Portugal, which is financed by European Union and Portuguese funds.

Please address correspondence to Manuel M.F. Martins (mmfmartins@fep.up.pt), Faculdade de Economia, Universidade do Porto, Rua Roberto Frias 4200-464 Porto, PORTUGAL; +351225571100 , ext. 284 (phone); +351225505050 (fax). 


\section{Introduction ${ }^{1}$}

The purpose of this paper is to formally examine whether there is significant evidence of asymmetries in the revealed preferences of the Euro Area monetary policymaker.

Most of the empirical analysis of monetary policy preferences has modeled the preferences of the policymaker as a symmetric quadratic loss function. Within that framework, Aguiar and Martins (2005), following an approach similar to Favero and Rovellis' (2003) study of the US case, have found that the aggregate Euro Area data uncover the existence of a well-defined monetary policy regime of strict inflation targeting with interest rate smoothing during 1995:I-2002:IV.

However, the hypothesis that the coefficients of policymakers' loss functions may not be identical across different states of the macroeconomy is receiving a growing interest in the literature. On one hand, Cukierman $(2000,2002)$ has suggested that credible central banks may have a precautionary demand for expansions, i.e., would rather have a positive than a negative output gap given a particular inflation level. On the other hand, Goodhart (1998) has argued that central banks with a need to build credibility may have a precautionary demand for price stability, i.e., would rather have inflation below than above the target, everything else equal.

Although discrimination between symmetry and asymmetry would clearly improve the knowledge about the preferences of monetary policymakers, examples of formal loss-function asymmetry tests do not abound in the literature. Most studies have tested for asymmetries in policy reaction functions, which, as reduced forms, are uninformative about the (structural) parameters of the loss function; while others have tested loss function asymmetry proper, but in the context of static or purely forwardlooking macro structures, which are not data consistent.

In this paper we relax the assumption of a symmetric quadratic policymaker loss function, allowing and testing for different coefficients across cyclical states of the economy, in a framework that encompasses the standard symmetric case. The baseline model consists of an aggregate demand-aggregate supply (AD-AS) macroeconomic structure and an Euler equation for optimal discretionary policy. The three equations are jointly estimated by the generalized method of moments (GMM), using the relevant cross-equation restrictions and the pre-defined policy targets. Among the estimates, we focus on the varying parameters of the loss function in order to conduct formal tests of asymmetry.

\footnotetext{
${ }^{1}$ We thank Fabio Canova's comments and suggestions to an earlier version of this paper. The usual disclaimer applies.
} 
The evidence is based on a sample beginning in 1995:I, a date that we - based on the record of European macroeconomic and monetary integration - assume as the beginning of a well-defined (although not formally until 1999:I) monetary policy regime in the aggregate Euro Area. The aggregate Euro Area data - quarterly 1995:I2005:II - is mostly from the last update of the European Central Bank's Area Wide Model Database (AWM12up5) available since August 2004². Regarding the output gap, we use a quasi-real-time output gap, in contrast with the ex-post measures often used in monetary policy analysis, as an attempt to approach the real-time data available to policymakers at the time of policy decisions.

The main result is that there is statistically significant evidence that the Euro Area monetary policymaker has had a precautionary demand for price stability during 19952005. This seems consistent with the fact that during the main part of this period a crucial task for the Euro-Area monetary policymaker - first a notional policymaker ahead of the EMU, throughout 1995-1998, and then the European Central Bank (ECB) proper, starting in 1999 - has been to establish its (anti-inflationary) credibility.

The rest of the paper is outlined as follows: In section 2 we briefly review the literature and recent empirical results on asymmetries of monetary policy preferences; then, in section 3, we present our model and econometric strategy; section 4 describes the data and discusses the empirical results, and section 5 shows some sensitivity checks; finally, section 6 offers some concluding remarks.

\section{The case for Asymmetric Monetary Policymaker's Preferences}

In this section we review the recent literature and main empirical results on asymmetric loss functions, and present the specific motivations for testing this asymmetry regarding the Euro Area policymaker.

Conventionally, policymakers' preferences have been modeled with symmetric quadratic loss functions, in which the same weights are attached to equally sized positive and negative deviations of the goal variables from their targets. Motivations for this assumption include plausibility, analytical tractability and clearness of the results. Yet, the hypothesis that the preferences of monetary policymakers may be asymmetric has received a lot of interest in two currents of the literature.

In the first current, Cukierman $(2000,2002)$ has argued that even though central bankers dislike deviations of inflation from the target as well as negative output gaps, for a given level of inflation they do not have interest in offsetting positive output gaps.

\footnotetext{
${ }^{2}$ We thank Elvira Rosati, of the ECB, for providing this latest version of the AWMD. 
The claim is that the political establishment is sensitive to the social costs of recessions, and that in democratic societies even independent and accountable central banks are not completely insensitive to social and political pressures. This hypothesis has practical appeal in as much as it seems consistent with many insiders' descriptions of policy, such as Blinder's (1998, p. 19-20) much cited: "In most situations the CB will take far more political heat when it tightens preemptively to avoid higher inflation than when it easies preemptively to avoid higher unemployment". Moreover, it has the theoretical appeal of offering an explanation for the inflationary bias in the monetary policy of the 1960s and 1970s that does not hinge on the Kydland-Prescott/Barro-Gordon (KP/BG) assumption that policymakers target output above its natural level. In fact, a policymaker with a loss function featuring Cukierman's asymmetry would tackle the uncertainty of policymaking choosing rather to err on the side of ease than on the side of tightening, i.e., it would have a precautionary demand for expansions - see Gerlach (2003) for a formal analysis, and Ruge-Murcia (2003a) and Cukierman and Gerlach (2003) for reduced-form tests of this hypothesis applied, respectively, to the US and 21 OECD countries.

In the second current of the literature, Goodhart (1998) has remarked that a policymaker trying to establish its credibility as an inflation fighter would react to uncertainty preferring negative rather than positive deviations from the inflation target. In this case, the policymaker would have a precautionary demand for price stability, from which a deflationary bias would arise. This type of bias that had been mentioned before by Fischer (1994) in the context of the creation of a new commitment to low inflation by developed countries during the 1980s. In such contexts of credibility buildup, the hypothesis of precautionary demand for price stability seems plausible, and could improve the quadratic functions as a description of the preferences of policymakers - see Ruge-Murcia (2003b) for an indirect test of this hypothesis for Sweden, Canada and the UK. Goodhart (1998) notes that, as inflation is typically a procyclical variable, this precautionary demand for price stability may offset Cukierman's precautionary demand for expansions.

Given these two conflicting hypothesis about the nature of the possible asymmetry in central banks' preferences, several researchers undertook the approach of testing for asymmetry encompassing both precautionary demands - for expansions and for price stability. Most of this research has focused on the estimation of non-linear policy reaction functions (for a variety of samples and with a variety of non-linear specifications) exploiting the well-known result that if an asymmetry in central bank 
preferences exists, then the optimal policy rule is non-linear - see Bec et al. (2002), Kim et al. (2005), Cukierman and Muscatelli (2002), Martin and Milas (2004), Karagedikli and Lees (2004), and Bruinshoofd and Candelon (2005).

However, evidence of non-linearity in policy reaction functions may be ultimately uninformative about the asymmetry of the policymaker's loss function. The reason is that policy reaction coefficients, as complex convolutions of the structural parameters, do not reveal the policymaker's preferences. Dealing with this issue requires the specification of a structural model of the economy so as to uncover the coefficients of the policymaker's loss function.

Examples of this structural approach are much more scarce, however, and seem limited to Dolado et al. (2004) and Surico (2003, 2004). Dolado et al. (2004) have shown that an asymmetric loss function of the linex functional form and a macroeconomic structure of the Rudebusch-Svensson type (Rudebusch and Svensson, 1999, 2002) generate an optimal policy reaction function that includes the conditional variance of inflation in addition to the standard reaction function regressors. With this setup, they found evidence of precautionary demand for price stability in the US only after 1983. Surico $(2003,2004)$ shows that the analytical solution of the policymaker optimization problem with a loss function with linex forms in both inflation and the gap, under a forward-looking AD-AS structure, results in an interest rate rule that includes the square of the output gap and of inflation deviations from target, and devised tests on its coefficients that allow for inference on the loss function non-linearity. While Surico (2003) finds that monthly Euro Area data for 1997:7-2002:10 reveals a precautionary demand for expansions, Surico (2004) finds a precautionary demand for expansions in the US monetary policy before 1979 and no sign of any asymmetry thereafter.

Both these studies seem to have some drawbacks, however. Dolado et al. (2004) have to restrict their policymaker loss function to a regime of strict inflation targeting and thus are not able to test for Cukierman's asymmetry. Moreover, their econometric strategy is not a truly simultaneous estimation of the macro system, as the conditional variance of inflation included in the optimal policy reaction function is generated in a first step prior to the rule estimation. In turn, Surico $(2003,2004)$ models the AS-AD structure of the economy with purely forward-looking equations and with instantaneous transmission of interest rate changes to output and inflation. The resulting lack of persistence and of policy lags implies that his model is not data-consistent. Due to these problems, it is hard to assess whether Dolado et al.'s and Surico's empirical results in the US case are incompatible or complementary. 
While the literature of formal analysis of central bank preferences' asymmetry, just briefly reviewed, exposes the need for methodological contributions, it also reveals that the Euro Area case has barely been studied to date - the only exception being Surico (2003). Yet, there are at least two compelling motivations for a study of the possible asymmetry in the preferences of the aggregate Euro Area monetary policymaker.

The first motivation is the ECB's own definition of price stability as "a year on year increase in the Harmonised Index of Consumer Prices for the Euro Area below 2 percent" (ECB, 2004, p.50), further clarified in the May 2003 statement that the ECB "aims to maintain inflation rates below but close to 2 percent over the medium term" (ECB, 2004, p. 51). This can be interpreted as an indication of asymmetric preferences, in the sense that 2 percent annual inflation is the ceiling consistent with price stability, with negative deviations from that limit preferred to positive deviations.

Second, the fact that the ECB has been created very recently may offer good substance for a case-study. In fact, the study of a new policymaker of a new monetary area is an exceptional opportunity to assess the plausibility of Goodhart's hypothesis that central banks engaged in the establishment of its credibility are prone to have a precautionary demand for price stability. From this point of view, Surico's (2003) evidence of a precautionary demand for expansions by the Euro Area policymaker between 1997 and 2002 is quite surprising.

We contribute to this literature with new evidence of the revealed preferences of the Euro-Area monetary policymaker. In view of the small-sample econometric difficulties in testing for varying policymaker's preference parameters with quarterly data starting in 1999, we stretch our sample back to 1995, thus adding a period of a notional Euro-Area policymaker ahead of the EMU (1995-1998) to the period of actual ECB policymaking (1999-2005). The extension of the estimation period back to 1995 is grounded on Aguiar and Martins' (2005) analysis that within the time span between the EMU Treaty (1992) and the actual monetary union, the evidence points to a welldefined aggregate monetary policy regime since $1995 .^{3}$ Yet, in section 5 below we inspect the sensitivity of the results to deviations from this sample period, including a shorter sample closer to the formal ECB era.

\footnotetext{
${ }^{3}$ In addition to reviewing the main European integration facts and the literature on the convergence of cycles in the EMU countries, Aguiar and Martins (2005) present econometric evidence of structural stability of an aggregate Euro-Area AS-AD system and of an aggregate policymaker's loss function coefficients since 1995 .
} 
The evidence is extracted using a framework that allows for testing the relevant asymmetries in the central bank loss function, given a data-consistent macroeconomic structure. The basis is Aguiar and Martins' (2005) GMM simultaneous estimation of an AS-AD macroeconomic structure with the policymaker's Euler equation, which is modified to allow for non-linearities in the Euler equation. Such non-linearities are clearly identified with asymmetries in the policymaker's loss function. In doing so, we are able to identify and, thus, retrieve the coefficients of the policymaker's preferences and of the macroeconomic structure (assumed to be linear). In addition to discriminating between precautionary demand for expansions and precautionary demand for price stability, the framework may also detect asymmetry in interest rate smoothing. This third type of asymmetry in preferences, although unexamined to date, is implicit in Goodhart's (1997) contention that because interest rate increases are normally seen as bad news while decreases are seen as good news, central bankers may tend to decrease rates smoothly and to increase them less frequently and in larger increments.

\section{A framework for testing for asymmetries in the preferences of the monetary policymaker}

This section presents the model and the econometric strategy for testing for asymmetries in the policymaker's preferences.

The model consists of an aggregate supply-aggregate demand (AS-AD) macroeconomic structure and a loss function describing the policy-maker's preferences.

In view of the generally recognized data-inconsistency of the dynamics of purely forward-looking specifications (documented by Estrella and Fuhrer (2002), for example) and considering the difficulties in identifying and estimating hybrid specifications with a small sample, we assume a simple AS-AD system of the Rudebusch and Svensson $(1999,2002)$ class. Versions of this type of macroeconomic structure have been profusely used in recent studies of monetary policy, including, for European countries, Taylor (1999) and Dolado et al. (2005). According to Rudebusch and Svensson (2002, pp. 421-422), their dynamic backward-looking AS-AD model is motivated by its "....congruence with actual central bank models, and empirical fit to the data." and it "...also appears to roughly capture the views about the dynamics of the economy held by many monetary policymakers."

We adopt the following version of the Rudebusch-Svensson model identified empirically with Euro-Area data by Aguiar and Martins (2005): 


$$
\left\{\begin{array}{l}
y_{t}=c_{1} y_{t-1}+c_{2} y_{t-2}+c_{3} y_{t-3}+c_{4}\left(i_{t-3}-\pi_{t-3}\right)+\varepsilon_{t}^{A D} \\
\pi_{t}=c_{5} \pi_{t-1}+c_{6} \pi_{t-2}+c_{7} \pi_{t-3}+\left(1-c_{5}-c_{6}-c_{7}\right) \pi_{t-4}+c_{8} y_{t}+c_{9} I \pi_{t-1}+\varepsilon_{t}^{A S} .
\end{array}\right.
$$

The first equation - the aggregate demand (AD) - links the output gap, $y$, to its past and to the real interest rate, $i-\pi$. The second equation - the aggregate supply (AS) relates inflation, $\pi$, to its lags, to the output gap, and to the lagged difference between imported and domestic inflation, $I \pi$. The innovations $\varepsilon_{t}^{A D}$ and $\varepsilon_{t}^{A S}$ are assumed to be iid normal with zero expected value. The AS equation is a version of the well known Gordon's Phillips relation, the triangle model of inflation explaining price dynamics with three basic elements - expectations and inertia, demand pressure and supply shocks. Dynamic homogeneity is imposed on the coefficients on lagged inflation, as the data does not reject that hypothesis in unconstrained estimation, with the advantage of reducing the number of coefficients to estimate and of complying with the natural rate hypothesis. As argued in more detail in Aguiar and Martins (2005), this model implies a dynamic behavior of the economy and a transmission of monetary policy consistent with the evidence in several studies of the aggregate Euro Area.

Following standard assumptions in the empirical literature of monetary policy, the policymaker's preferences are modeled as an inter-temporal loss functional in which, at each period, the loss function depends on the square of the deviations of inflation and the output gap from desired levels ( $\pi^{*}$ and zero, respectively) as well as on the square of the change in the interest rate (reflecting interest rate smoothing). Future values are discounted at rate $\delta$, and the weights $\phi, \lambda$, and $\mu$ are nonnegative. Assuming a discretionary policy regime, for the sake of realism and estimation feasibility, the optimization problem solved by the central banker is a closed-loop system. At each period, given the observed state of the economy, the policymaker chooses the value for the policy control variable - the interest rate $i$ - that minimizes the loss functional, subject to the dynamic structure of the economy,

$$
\operatorname{Min}_{i_{t}} E_{t} \sum_{\tau=0}^{\infty} \delta^{\tau} \frac{1}{2}\left[\phi\left(\pi_{t+\tau}-\pi^{*}\right)^{2}+\lambda y_{t+\tau}^{2}+\mu\left(i_{t+\tau}-i_{t+\tau-1}\right)^{2}\right]
$$

subject to system (1), $\forall t$.

Asymmetry in the policymaker's preferences means that the structural weights $\phi$, $\lambda$, and $\mu$ depend on the appropriate state of the economy. Restricting these functions to simple threshold (bilinear) models, the types of asymmetric preferences suggested in the literature may be written as follows, reflecting (i) Cukierman's (2000) precautionary 
demand for expansions, (ii) Goodhart's (1998) precautionary demand for price stability and (iii) Goodhart's (1997) interest rate smoothing asymmetry:

$$
\begin{aligned}
& \lambda=\left.\lambda\right|_{y_{t+\tau} \geq 0} \times 1_{\left[y_{t+\tau} \geq 0\right]}+\left.\lambda\right|_{y_{t+\tau}<0} \times 1_{\left[y_{t+\tau}<0\right]} \\
& \phi=\left.\phi\right|_{\pi_{t+\tau} \geq \pi^{*}} \times 1_{\left[\pi_{t+\tau} \geq \pi^{*}\right]}+\left.\phi\right|_{\pi_{t+\tau}<\pi^{*}} \times 1_{\left[\pi_{t+\tau}<\pi^{*}\right]} \\
& \mu=\left.\mu\right|_{\Delta i_{t+\tau} \geq 0} \times 1_{\left[\Delta i_{t+\tau} \geq 0\right]}+\left.\mu\right|_{\Delta i_{t+\tau}<0} \times 1_{\left[\Delta i_{t+\tau}<0\right]}
\end{aligned}
$$

where $1_{[.]}$is a Heaviside function that equals one if the argument-condition holds and zero otherwise. Under (3), the loss function turns into a threshold quadratic function in which the weights associated with the squared deviations of each goal-variable from its desired level are allowed to switch when each goal-variable is expected to be above or below its desired level. The modified policymaker's optimization problem is, then,

$$
\begin{aligned}
\operatorname{Min}_{i_{t}} E_{t} \sum_{\tau=0}^{\infty} \delta^{\tau} \frac{1}{2}[ & \left(\left.\phi\right|_{\pi_{t+\tau} \geq \pi^{*}} \times 1_{\left[\pi_{t+\tau} \geq \pi^{*}\right]}+\left.\phi\right|_{\pi_{t+\tau}<\pi^{*}} \times 1_{\left[\pi_{t+\tau}<\pi^{*}\right]}\right)\left(\pi_{t+\tau}-\pi^{*}\right)^{2} \\
& +\left(\left.\lambda\right|_{y_{t+\tau} \geq 0} \times 1_{\left[y_{t+\tau} \geq 0\right]}+\left.\lambda\right|_{y_{t+\tau}<0} \times 1_{\left[y_{t+\tau}<0\right]}\right)\left(y_{t+\tau}\right)^{2} \\
& \left.+\left(\left.\mu\right|_{\Delta i_{t+\tau} \geq 0} \times 1_{\left[\Delta i_{t+\tau} \geq 0\right]}+\left.\mu\right|_{\Delta i_{t+\tau}<0} \times 1_{\left[\Delta i_{t+\tau}<0\right]}\right)\left(i_{t+\tau}-i_{t+\tau-1}\right)^{2}\right]
\end{aligned}
$$

s.t. system (1), $\forall t$.

For example, if the policymaker has a precautionary demand for expansions, then $\left.\lambda\right|_{y_{t+\tau} \geq 0}<\left.\lambda\right|_{y_{t+\tau}<0}$, and interest rates are changed - at moment $t$ - more (less) aggressively when the expected output gap - at moment $t+\tau$ - is negative (positive), for the same size of deviation from zero.

This specification encompasses the symmetric case, in which the weights $\phi, \lambda$, and $\mu$, are constant. In addition, it is flexible enough to allow for testing asymmetry of the loss function weights simultaneously or individually, thus permitting a clarification of the origin of the possible asymmetry. The choice of a bilinear model is aimed at keeping the loss function and the corresponding Euler equation as simple as possible; this seems reasonable in view of the limited data and of the lack of a-priori information about the functional form of the possible asymmetry. ${ }^{4}$

The Euler equation for this problem is the following expression describing the optimal path for the policy instrument, $i$, as function of the expected values of the state variables of the economy, $\pi$ and $y$ :

\footnotetext{
${ }^{4}$ One functional form often used in the recent literature, the linex function - see Nobay and Peel (2003) and Ruge-Murcia (2004) - behaves quite similarly to our threshold quadratic specification for realistic parameters, but results in a more complex Euler equation and could lead to empirical problems due to the limitations of the data sample.
} 


$$
\begin{aligned}
& E_{t} \sum_{\tau=0}^{\infty} \delta^{\tau}\left(\left.\phi\right|_{\pi_{t+\tau} \geq \pi^{*}} \times 1_{\left[\pi_{t+\tau} \geq \pi^{*}\right]}+\left.\phi\right|_{\pi_{t+\tau}<\pi^{*}} \times 1_{\left[\pi_{t+\tau}<\pi^{*}\right]}\right)\left(\pi_{t+\tau}-\pi^{*}\right) \frac{\partial \pi_{t+\tau}}{\partial i_{t}} \\
+ & E_{t} \sum_{\tau=0}^{\infty} \delta^{\tau}\left(\left.\lambda\right|_{y_{t+\tau} \geq 0} \times 1_{\left[y_{t+\tau} \geq 0\right]}+\left.\lambda\right|_{y_{t+\tau}<0} \times 1_{\left[y_{t+\tau}<0\right]}\right) y_{t+\tau} \frac{\partial y_{t+\tau}}{\partial i_{t}} \\
+ & \left(\left.\mu\right|_{\Delta i_{t+\tau} \geq 0} \times 1_{\left[\Delta_{t+\tau} \geq 0\right]}+\left.\mu\right|_{\Delta i_{t+\tau}<0} \times 1_{\left[\Delta i_{t+\tau}<0\right]}\right)\left(i_{t}-i_{t-1}\right) \\
- & \left(\left.\mu\right|_{\Delta i_{t+\tau} \geq 0} \times 1_{\left[\Delta_{t+\tau} \geq 0\right]}+\left.\mu\right|_{\Delta i_{t+\tau}<0} \times 1_{\left[\Delta i_{t+\tau}<0\right]}\right) \delta E_{t}\left(i_{t+1}-i_{t}\right)=0 .
\end{aligned}
$$

Because of the persistence in the AS-AD system, the Euler equation has an infinite horizon, and thus cannot be used directly in empirical work. With this regard, we adopt the approach devised by Favero and Rovelli (2003), and truncate expression (5) at 4 quarters ahead. This horizon seems realistic, in view of the ability of forecasting macroeconomic conditions by actual policymakers - see Aguiar and Martins (2005) for further discussions and sensitivity analysis. The specification proceeds with the expansion of the partial derivatives in (5) as functions of the relevant AS-AD coefficients in (1), in order to include the cross-equation restrictions that ensure that the minimization of the policymaker's loss function is subject to the constraints given by the structure of the economy. The resulting expression, supplemented with an innovation for estimation purposes, is

$$
\begin{aligned}
& E_{t} \delta^{3}\left(\left.\phi\right|_{\pi_{t+3} \geq \pi^{*}} \times 1_{\left[\pi_{t+3} \geq \pi^{*}\right]}+\left.\phi\right|_{\pi_{t+3}<\pi^{*}} \times 1_{\left[\pi_{t+3}<\pi^{*}\right]}\right)\left(\pi_{t+3}-\pi^{*}\right)\left(c_{8} c_{4}\right) \\
+ & E_{t} \delta^{4}\left(\left.\phi\right|_{\pi_{t+4} \geq \pi^{*}} \times 1_{\left[\pi_{t+4} \geq \pi^{*}\right]}+\left.\phi\right|_{\pi_{t+4}<\pi^{*}} \times 1_{\left[\pi_{t+4}<\pi^{*}\right]}\right)\left(\pi_{t+4}-\pi^{*}\right)\left(c_{8} c_{1} c_{4}+c_{5} c_{8} c_{4}\right) \\
+ & E_{t} \delta^{3}\left(\left.\lambda\right|_{y_{t+3} \geq 0} \times 1_{\left[y_{t+3} \geq 0\right]}+\left.\lambda\right|_{y_{t+3}<0} \times 1_{\left[y_{t+3}<0\right]}\right) y_{t+3} c_{4} \\
+ & E_{t} \delta^{4}\left(\left.\lambda\right|_{y_{t+4} \geq 0} \times 1_{\left[y_{t+4} \geq 0\right]}+\left.\lambda\right|_{y_{t+4}<0} \times 1_{\left[y_{t+4}<0\right]}\right) y_{t+4}\left(c_{1} c_{4}\right) \\
+ & \left(\left.\mu\right|_{\Delta i_{t+0} \geq 0} \times 1_{\left[\Delta i_{t+0} \geq 0\right]}+\left.\mu\right|_{\Delta i_{t+0}<0} \times 1_{\left[\Delta i_{t+0}<0\right]}\right)\left(i_{t}-i_{t-1}\right) \\
- & \left(\left.\mu\right|_{\Delta i_{t+1} \geq 0} \times 1_{\left[\Delta i_{t+1} \geq 0\right]}+\left.\mu\right|_{\Delta i_{t+1}<0} \times 1_{\left[\Delta t_{t+1}<0\right]}\right) \delta E_{t}\left(i_{t+1}-i_{t}\right)+\varepsilon_{t}^{I R}=0 .
\end{aligned}
$$

Simultaneous estimation of the system of 3 equations composed of the AS-AD system (1) and the Euler equation (6), delivers the parameters describing the monetary policy regime and the AS-AD coefficients. Because expectations of future inflation, output gaps and interest rates are not available in the data, they are replaced by actual observations and, therefore, GMM are the appropriate estimators, assuming that the policymaker's expectations errors are not correlated with the information available at the time of expectations formation. As regards the instrument set to form the orthogonality conditions, we follow Aguiar and Martins (2005) and use the second, third and fourth lags of all the system's variables as instruments, and base inference in a heteroskedasticity and auto-correlation-consistent variance-covariance matrix. 
In order to cover the three types of asymmetry in the policymaker's preferences identified in the literature, estimation is carried out sequentially allowing each of the loss function weights $\phi, \lambda$, and $\mu$ to vary with the state of the corresponding target variable, and then concludes with a joint test. Statistical inference is based on individual significance tests and Wald tests of the null hypothesis of no asymmetry. In agreement with standard practice in the literature, the weight $\phi$ is restricted to $\phi=1$ when not asymmetric; likewise, when $\phi$ is allowed to be asymmetric, the sum $\left.\phi\right|_{\pi_{t+\tau} \geq \pi^{*}}+\left.\phi\right|_{\pi_{t+\tau}<\pi^{*}}$ is restricted to equal 2, to keep consistency with the null of symmetry $\left.\phi\right|_{\pi_{t+\tau} \geq \pi^{*}}=\left.\phi\right|_{\pi_{t+\tau}<\pi^{*}}=1$.

\section{Results: the case of the Euro Area}

In this section we first describe the data and, then, conduct the tests for asymmetry in the monetary policymaker's loss function and assess the results, including a comparison of the asymmetric preferences results with those of a standard quadratic central bank loss function.

All data series are quarterly time-series for 1995:I-2005:II for the aggregate Euro Area. The source is the ECB, except for the output gap, which has been computed by the authors as described below. For 1995:I-2003:IV, the figures are those of the latest update of the ECB's Area Wide Model Database (AWM12up5, available since September 2004), while for 2004:I-2005:II consistent updates have been obtained from the latest ECB's monthly bulletin.

The inflation rate is 100 times the difference of the log of quarterly GDP deflator to the same quarter in the previous year. It could be argued that, to agree with the ECB's definition of price stability, the annualized inflation rate should be computed from the harmonized index of consumer prices (HICP), instead of our choice of the GDP deflator. But, because $\pi$ must relate closely to both the policy decisions and, in the AS equation, to the output gap, the growth of the GDP deflator is more adequate than the HICP. ${ }^{5}$ In any case, the sample average of $\pi, 1.923$ percent, is identical to the average of the analogous rate of growth of the HICP, and the volatility of HICP inflation is only slightly below that of $\pi$.

\footnotetext{
5 This argument is, in fact, parallel to the reason that lies behind the standard use of a 3-month interest rate instead of a shorter money market rate, which would be closer to the actual policy instrument - the fact that $i$ must, in this class of models, simultaneously play the role of policy instrument and connect closely to aggregate demand decisions.
} 
The nominal short-term interest rate is the quarterly average of the 3-month interest rate Euribor, in percentage points. The proxy for exogenous supply shocks is the lagged difference between imported and domestic inflation, with imported inflation computed as 100 times the annual difference of the log of the Area's imports deflator. The output gap, in percentage points, is the log difference between real GDP and a stochastic trend.

The output gap has been estimated by the authors from a univariate unobservable components model of log real output, specifically a local linear trend model augmented with an autoregressive cycle. As the maximum likelihood estimate of the variance of the innovation to the stochastic drift in the trend is biased towards zero, we employ Stock and Watson's (1998) procedure to obtain a median unbiased estimation of this variance, and then constrain the kalman filter estimation of the trend-cycle model accordingly. ${ }^{6}$ The output gap time-series is not given by the end-of-sample kalman smoother, but rather the updated one-step-ahead forecasts given directly by the kalman filter (see Harvey, 1989). This quasi real-time estimate, in comparison with the two-sided output gaps that have been used in the tests for asymmetry of policy preferences in previous literature, is conceptually closer to the information available to policymakers at the time of policy decisions. ${ }^{7}$

The framework for testing loss function asymmetry requires a pre-defined inflation target, $\pi^{*}$. In view of the definition of price stability by the ECB, reviewed above, a value of 2 percent for $\pi^{*}$ is a consensual choice; this target has also been used, in the related literature, by Dolado et al. (2005) and by Surico (2003).

Figure 1 shows, for the sample period, the data on the relevant arguments in the policymaker's loss function, together with the corresponding desired values, which are the threshold levels in the asymmetry tests -0 for $y$ and $\Delta i$, and 2 for $\pi$.

Table 1 summarizes the tests for each asymmetry - precautionary demand for expansions, precautionary demand for price stability and asymmetric interest rate smoothing - as well as the joint tests of these three type of asymmetries. In order to focus the analysis, we report only the loss function coefficients, and the corresponding

\footnotetext{
${ }^{6}$ Notice that the output gap is estimated with the whole available time-series of real output, 1970:I2005:II, even though only gaps for 1995:I-2005:II are used in the subsequent estimations in the paper. All data and replication files are available from the authors upon request, including the Gauss codes for computing the output gap.

${ }^{7}$ Our concept of quasi-real time output gap differs slightly from Orphanides and Van Norden's (2002) homonym concept, in that even though the kalman filter's one-step-ahead forecasts of trend output are computed from past data of output only, the filter uses the estimates for the UC model hyper-parameters that have been estimated using the whole sample.
} 
test statistics, even though these have been obtained in a joint GMM estimation of the AS-AD-Euler system, as discussed in section 3, above.

The table shows no sign of precautionary demand for expansions, as neither $\left.\lambda\right|_{y_{t+\tau} \geq 0}$, nor $\left.\lambda\right|_{y_{t+\tau}<0}$ are statistically significant, nor the hypothesis that $\left.\lambda\right|_{y_{t+\tau} \geq 0}=\left.\lambda\right|_{y_{t+\tau}<0}$ can be rejected at conventional significance levels, irrespectively of modeling this type of asymmetry individually or jointly.

Moreover, the evidence indicates that the output gap, $y$, is not a relevant argument in the Euro Area's policymaker loss function, as $\lambda$ is statistically insignificant not only when some source of loss function asymmetry is allowed for, but also (results not reported) when the loss function is of the standard quadratic form.

When, in accordance with this evidence, regimes of strict inflation targeting are adopted - restricting $\lambda=0$ - there is evidence in favor of the hypothesis of precautionary demand for price stability. In fact, the hypothesis that $\left.\phi\right|_{\pi_{t+\tau} \geq \pi^{*}}=\left.\phi\right|_{\pi_{t+\tau}<\pi^{*}}$ can be rejected at 1 percent of significance, and the estimates for $\left.\phi\right|_{\pi_{t+\tau} \geq \pi^{*}}, 1.366$, and $\left.\phi\right|_{\pi_{t+\tau}<\pi^{*}}, 0.634$, mean that the monetary policymaker has weighted positive deviations of inflation from the target twice as much as negative deviations.

The estimates of $\left.\phi\right|_{\pi_{t+\tau} \geq \pi^{*}}$ and $\left.\phi\right|_{\pi_{t+\tau}<\pi^{*}}$ are unchanged when the asymmetry regarding the objective of price stability is combined with interest rate smoothing asymmetry (last line of table 1), and the p-value of the test for the hypothesis of precautionary demand for price stability is still at 1 percent. Regarding interest rate smoothing itself, there is no evidence in favor of this type of asymmetry throughout the entire table 1, as the hypothesis that $\left.\mu\right|_{\Delta i_{t+\tau} \geq 0}=\left.\mu\right|_{\Delta i_{t+\tau}<0}$ is never rejected at conventional significance levels.

In short, during 1995:I-2005:II the policy actions of the Euro Area monetary policymaker reveal a regime of strict inflation targeting with interest rate smoothing and a precautionary demand for price stability. ${ }^{8}$ In contrast with Surico's (2003) inference of a precautionary demand for expansions, this revealed asymmetry is consistent with the ECB's definition of price stability and with the priority of credibility-building by a recently created monetary authority. ${ }^{9}$

\footnotetext{
${ }^{8}$ The asymmetry tests results have proven to be robust to a cross-check (not reported here) consisting of testing for asymmetry in each loss function coefficient using as threshold variable all possible alternative target-variables in the loss function.

${ }^{9}$ The disparity between our results and Surico's - which is beyond the scope of this paper to scrutinize could result from differences in the model as well as in data: Surico (2003) uses a different sample and
} 
Table 2 presents complete estimates of the selected model, in the upper panel, together with those of the parallel model with standard quadratic policy preferences, in the lower panel. The case of flexible inflation targeting $-\lambda$ not restricted to $0-$ has not been selected because of the insignificance of $\lambda$ found above (also found by Aguiar and Martins, 2005, with an alternative measure of the output gap).

The 1.837 percent inflation target estimated in the symmetric model, with a 95 percent confidence interval of $[1.75,1.92]$, is consistent with the downward bias relative to 2 percent in the asymmetric preferences model. The results in the table also suggest that the asymmetry in the loss function does not influence the AS-AD coefficients, which are estimated with the expected signs, reasonable magnitudes and good precision, and are remarkably similar across the two specifications (symmetric and asymmetric) of policy-maker's preferences. The converse remains to be assessed - if different AS-AD specifications interfere with the asymmetry of the loss function. This is one of the sensitivity checks to be conducted next.

\section{Sensitivity checks}

This section reports some sensitivity exercises to which we have submitted the results, concerning (i) the beginning date of the sample; (ii) the truncation of the Euler equation; (iii) exclusion of interest rate smoothing from the central bank's loss function; (iv) an alternative output gap; and (v) variants of the AS-AD structure.

\section{Sensitivity to the date of emergence of the monetary policy regime}

In view of the non-institutional basis for identification, by Aguiar and Martins (2005), of 1995:I as the beginning date of the Euro Area notional policy regime, we now check the sensitivity of the tests for asymmetry to changes in the start of the sample period.

Table 3 shows, for selected samples beginning at 1996:I, 1997:I and 1998:I, the results of the tests of the hypothesis of precautionary demand for price stability (results regarding the significance of the output gap, not reported for space conservation, are entirely consistent with those in Table 1). The check does not proceed after 1998:I due to the reduced number of observations. Yet, from the 30 observations in this last sample only the first 4 are pre-EMU quarters, so that the results may be considered an approximation to a test of asymmetric policy preferences in the EMU.

periodicity (monthly data 1997:7-2002:10), a different computation of the output gap (two-sided HodrickPrescott-filter of industrial production) and a different structural macro model (purely forward-looking AS-AD model without any policy lags). 
Overall, the estimates of the weights attached by the policy-maker to positive and negative deviations of inflation from 2 percent are remarkably consistent with those obtained from the full sample, and the hypothesis of no precautionary demand for price stability can be rejected at standard confidence levels.

\section{Sensitivity to truncation of Euler equation}

Since the Euler equation used in estimation is a finite approximation to the infinite terms' equation (5), we now inspect the robustness of the asymmetry tests results to larger forecast horizons of the policy-maker.

Table 4 reports the results of the relevant tests - precautionary demand for price stability in strict inflation targeting regimes - for truncations at 5 and 6 quarters ahead i.e. $\tau=5$, and $\tau=6$ in equation (5). Even though policy-makers may possibly set interest rates reacting to output gaps and inflation forecasted up until more than one and a half years ahead, further extension of the Euler equation is problematic because of the number and nonlinear combinations of parameters involved (Favero and Rovelli, 2003), which is particularly critical in the case of small samples.

Clearly, the table shows that the evidence in favour of a precautionary demand for price stability in the Euro Area, reported in table 1, is robust to expanding the policymaker's forecast horizon up to one and a half years. ${ }^{10}$

\section{Sensitivity to inflation targeting without interest rate smoothing}

While the ex-ante inclusion of interest rate smoothing as a policy goal in the policymaker's loss function is standard in empirical studies, as it is needed for a suitable replication of the inertia observed in interest rates, it could be argued that this may be a result of the assumed macroeconomic structure rather than a policy objective by itself. Hence, we now check whether the asymmetry tests results are sensitive to the exclusion of interest rate smoothing from the policymaker's loss function.

Table 5 reveals that under the restriction $\mu=0$ there is still no evidence allowing for rejection of the null hypothesis of no precautionary demand for expansions, while, in contrast, the hypothesis of no precautionary demand for price stability is again rejected at standard confidence levels. Consistently with our previous results, the detection of asymmetric inflation preferences appears clearly in the regime of strict inflation targeting, which is favored by the data against the flexible inflation targeting regime.

\footnotetext{
${ }^{10}$ Allowing also for asymmetry in the preferences regarding the output gap - results not reported for space conservation - does not change the statistical evidence in favour of a precautionary demand for price stability.
} 


\section{Sensitivity to an alternative measure of the Output Gap}

As explained above, our output gap measure is the kalman filter estimate of a univariate structural time series model of log real output. We have labelled this gap a quasi-real time output gap, in the sense that it results from a one-sided univariate filter of real output (conditional on the whole sample estimates of the model hyper-parameters), and have argued that it may be closer to the actual information available to policy-makers when setting interest rates than the standard two-sided filters. We now check whether results would change substantially with a two-sided and perhaps more conventional measure of the output cycle - the deviation of log real output from its Hodrick-Prescott filter trend.

As Table 6 shows, the results are entirely consistent with the baseline results reported in Table 1. First, there is no evidence of asymmetry in the preferences for interest rate smoothing and no evidence of precautionary demand for expansions; second, there is evidence of precautionary demand for price stability at very low significance levels, irrespective of the restrictions that are imposed on the other arguments of the policy-maker's loss function. The estimates of the policy-maker's loss function weights on inflation rates above 2 percent range from 1.353 to 1.493 (weights on inflation rates below 2 percent range from 0.647 to 0.507 ), which is in line with the estimates of table 1.

\section{Sensitivity to variants of the AS-AD structure}

The aggregate demand-aggregate supply structure (1) has been identified empirically, with Euro Area data including a quasi-real time output gap, starting out from the Rudebusch and Svensson $(1999,2002)$ model of the US economy. Although rooted in this benchmark, system (1) deviates from it in two main features. First, in the AS equation, inflation is explained by contemporaneous rather than lagged output gap. Second, in the AD equation, the output gap is explained by a third lag of the real interest rate, rather than a real rate computed as its average during the previous four quarters.

We now check if results of the asymmetry tests are robust to alternative lagstructures of the AD and AS equations. ${ }^{11}$ Specifically, we vary the lag of the real

\footnotetext{
${ }^{11}$ Our framework would also allow for a joint test of the hypothesis of asymmetry in the policy-maker's preferences and of nonlinearity in the aggregate-supply equation. However, succeeding in such an econometric task with GMM estimation requires far more data than is currently available for meaningful analysis of aggregate Euro-Area policy-making, and thus we defer such exercise for future research.
} 
interest rate in the $\mathrm{AD}$ equation from one through four quarters, and the lag of the output gap from zero to one quarter, thus encompassing the whole range of lags of the Rudebusch-Svensson structure. Results are summed-up in table 7, including the Rudebusch and Svensson (1999) US-economy specification in the last four lines.

Table 7 confirms that there is no evidence of asymmetry between interest rate increases and declines. In what regards deviations of output from its trend, there is also no statistical evidence of asymmetry, neither precautionary demand for expansions nor contractions.

The table shows that the estimates of the policy-maker's loss function weights on positive deviations of inflation from the target are always larger than the weights on negative deviations, consistently with the results in the baseline model. These weights range, respectively, from 1.322 to 1.718 , and from 0.678 to 0.282 . Across the eight alternative AS-AD systems, there is always 1-percent significant evidence of precautionary demand for price stability, so long as the loss function is specified as a strict inflation targeting regime. When the policy-maker's preferences are allowed to include directly an output stabilisation objective, the evidence of precautionary demand for price stability remains 10-percent significant in six out of the eight alternative systems, and in all cases the estimates of the inflation weights hardly change.

\section{Concluding Remarks}

This paper has tested for asymmetries in the preferences of the aggregate Euro Area monetary policymaker, looking at deviations from the standard quadratic loss function that have been suggested in recent literature - precautionary demand for expansions, precautionary demand for price stability, and interest rate smoothing asymmetry.

The results obtained reject flexible inflation targeting in favor of strict inflation targeting, which corroborates previous evidence that we have obtained under symmetry. As to the specific purpose of this paper, there is evidence that the Euro-Area monetary policymaker has revealed a precautionary demand for price stability throughout 19952005, weighting deviations of inflation above 2 percent twice as much as deviations below 2 percent. This type of asymmetry is consistent with the ECB's definition of price stability and with the priority of credibility-building by a recently created monetary authority.

The evidence of precautionary demand for price stability has proved to be robust to several variations in the empirical framework. This type of asymmetry persists under 
a conventional (Hodrick-Prescott filter based) measure of the output gap, and under variants of the aggregate demand-aggregate supply structure of the RudebuschSvensson class, including the system specified by these authors for the US economy. Moreover, the evidence of precautionary demand for price stability holds out in samples beginning as late as 1998:I, which is very close to the EMU years. Yet, this evidence should be put to the test once enough new data allow for the estimation of strictly post1999 monetary policy preferences with acceptable degrees of freedom.

Future empirical research on the Euro Area case, when enough data on the Area policy regime and macro structure becomes available, should also test simultaneously for asymmetries in the policy-maker's preferences and for nonlinearity of the AS relation, and experiment with hybrid forward and backward-looking AS-AD equations to model the macro structure of the Area. 


\section{References}

Aguiar, Alvaro, and Manuel M. F. Martins. (2005) "The Preferences of the Euro Area Monetary Policymaker," Journal of Common Market Studies, Vol. 43, No. 2, June, 221-50.

Bec, Frédérique, Mélika Ben Salem, and Fabrice Collard. (2002) “Asymmetries in Monetary Policy Reaction Function: Evidence for US, French and German Central Banks," Studies in Nonlinear Dynamics \& Econometrics, Vol. 6, No. 2, July, article 3.

Blinder, Alan S. (1998) Central Banking in Theory and Practice, Lionel Robbins Lectures, (Cambridge and London: MIT Press).

Bruinshoofd, Allard, and Bertrand Candelon (2005) "Nonlinear monetary policy in Europe: fact or myth?” Economics Letters, Vol. 86, No. 3, March, 399-403.

Cukierman, Alex. (2000) “The Inflation Bias Result Revisited,” Mimeo, Berglas School of Economics, Tel-Aviv University, April $25^{\text {th }}$.

Cukierman, Alex. (2002) “Are Contemporary Central Banks Transparent about Economic Models and Objectives and What Difference Does It Make?" Federal Reserve Bank of St. Louis Review, Vol. 84, No. 4, July-August, 15-35.

Cukierman, Alex, and Stefan Gerlach. (2003) "The Inflation Bias Revisited: Theory and Some International Evidence," The Manchester School, Vol. 71, No. 5, September, 541-65.

Cukierman, Alex, and Anton Muscatelli. (2002) "Do Central Banks have Precautionary Demands for Expansions and for Price Stability?” CESIFO Working Paper $n^{\circ} 764$, August.

Dolado, Juan, Ramón Maria-Dolores, and Manuel Naveira. (2005) “Are Monetary Policy Reaction Functions Asymmetric? The Role of Nonlinearity in the Phillips Curve, “European Economic Review, Vol. 49, No. 2, February, 485-503.

Dolado, Juan, Ramón Maria-Dolores, and Francisco Ruge-Murcia. (2004) "Non-Linear Monetary Policy Rules: Some New Evidence for the US," Studies in Nonlinear Dynamics and Econometrics, Vol. 8, No. 3, September, Article 2.

Estrella, Arturo and Jeffrey Fuhrer. (2002) "Dynamic Inconsistencies: Counterfactual Implications of a Class of Rational Expectations Models," American Economic Review, Vol. 92, No. 4, September, 1013-1028. 
European Central Bank.(2004) The Monetary Policy of the ECB, (Frankfurt: European Central Bank), $2^{\text {nd }}$ edition.

Favero, Carlo A., and Ricardo Rovelli. (2003) "Macroeconomic Stability and the Preferences of the Fed: A Formal Analysis, 1961-98," Journal of Money, Credit, and Banking, Vol. 35, No. 4, August, 545-56.

Fischer, Stanley. (1994) “Modern Central Banking”, pp. 262-308 in Forrest Capie et al. (Eds), The future of central banking: the tercentenary symposium of the Bank of England, (Cambridge; New York and Melbourne: Cambridge University Press).

Gerlach, Stefan. (2003) "Recession Aversion, Output and the Kydland-Prescott BarroGordon Model,” Economics Letters, 81 (3), December 2003, 389-94.

Goodhart, Charles A. E.. (1998) “Central Bankers and Uncertainty”, London School of Economics, Financial Markets Group Special Paper Series no. 106, October.

Goodhart, Charles A. E.. (1997) "Why Do the Monetary Authorities Smooth Interest Rates?” pp. 119-74 in Stefan Collignon (Ed.), European monetary policy, (London and Washington D.C.: Pinter).

Harvey, Andrew C. (1989) Forecasting, Structural Time Series Models and the Kalman Filter (Cambridge: Cambridge University Press).

Karagedikli, Özer, and Kirdan Lees, (2004) "Do Inflation Targeting Central Banks Behave Asymmetrically? Evidence from Australia and New Zealand," Reserve Bank of New Zealand Discussion Paper no 2004/02, April.

Kim, Dong H., Denise R. Osborn, and Marianne Sensier. (2005) "Nonlinearity in the Fed's Monetary Policy Rule," Journal of Applied Econometrics, Vol. 20, No. 5, JulyAugust, 621-640.

Martin, Christopher, and Costas Milas. (2004) "Modelling Monetary Policy: Inflation Targeting in Practice," Economica, Vol. 71, No. 282, May, 209-21.

Nobay, A. Robert, and David A. Peel. (2003) "Optimal Discretionary Monetary Policy in a Model of Asymmetric Central Bank Preferences," Economic Journal, Vol. 113, No. 489, July, 657-65.

Orphanides, Athanasios, and Simon van Norden. (2002) "The Unreliability of OutputGap Estimates in Real Time," Review of Economics and Statistics, Vol. 84, No. 4, November, 569-83. 
Rudebusch, Glenn and Lars Svensson (2002) "Eurosystem Monetary Targeting: Lessons from U.S. Data," European Economic Review, Vol. 46, No. 3, March, 417442.

Rudebusch, Glenn and Lars Svensson (1999). "Policy Rules for Inflation Targeting," (pp. 203-246) In John Taylor (Ed.) Monetary Policy Rules. Chicago, University of Chicago Press, National Bureau of Economic Research Conference Report.

Ruge-Murcia, Francisco (2004) "The Inflation Bias When the Central Bank Targets the Natural Rate of Unemployment," European Economic Review, Vol. 48, No. 1, February, 91-107.

Ruge-Murcia, Francisco (2003b) "Inflation Targeting under Asymmetric Preferences," Journal of Money, Credit, and Banking, Vol. 35, No. 5, October, 763-85.

Ruge-Murcia, Francisco (2003a) "Does the Barro-Gordon Model Explain the Behavior of US Inflation? A Reexamination of the Empirical Evidence," Journal of Monetary Economics, 50 (6), September, 1375-90.

Stock, James, and Mark Watson. (1998) "Median Unbiased Estimation of a Coefficient Variance in a Time-Varying Parameter Model," Journal of the American Statistical Association, Vol. 93, No. 441, March, 349-358.

Surico, Paolo. (2004) "Inflation Targeting and Nonlinear Policy Rules: the Case of Asymmetric Preferences," CESIFO Working Paper n 1280, September.

Surico, Paolo. (2003) "Asymmetric Reaction Functions for the Euro Area," Oxford Review of Economic Policy, Vol. 19, No. 1, Spring, 44-57.

Taylor, John B. (1999) "The Robustness and Efficiency of Monetary Policy Rules as Guidelines for Interest Rate setting by the European Central Bank", Journal of Monetary Economics, Vol. 43, No. 3, June, 12-13. 


\section{Figure 1. Loss Function Variables}

Euro Area 1995:I-2005:II

Output Gap

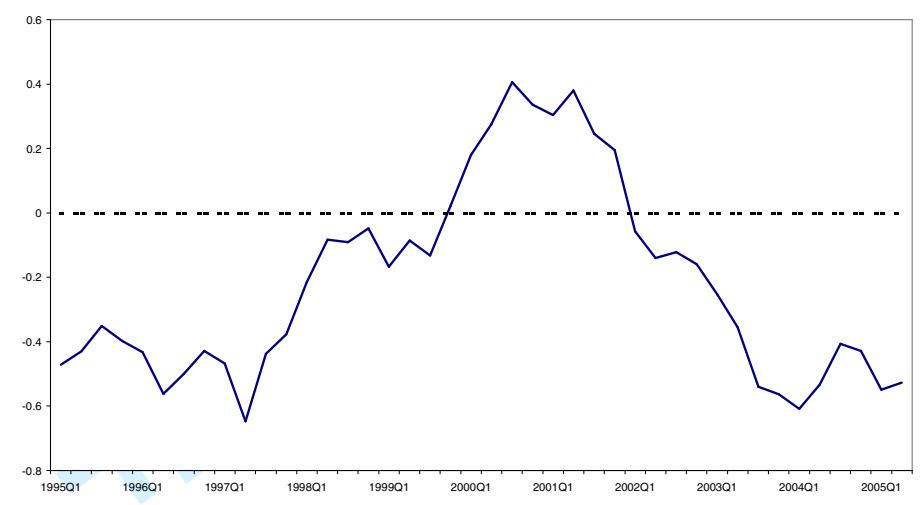

Inflation

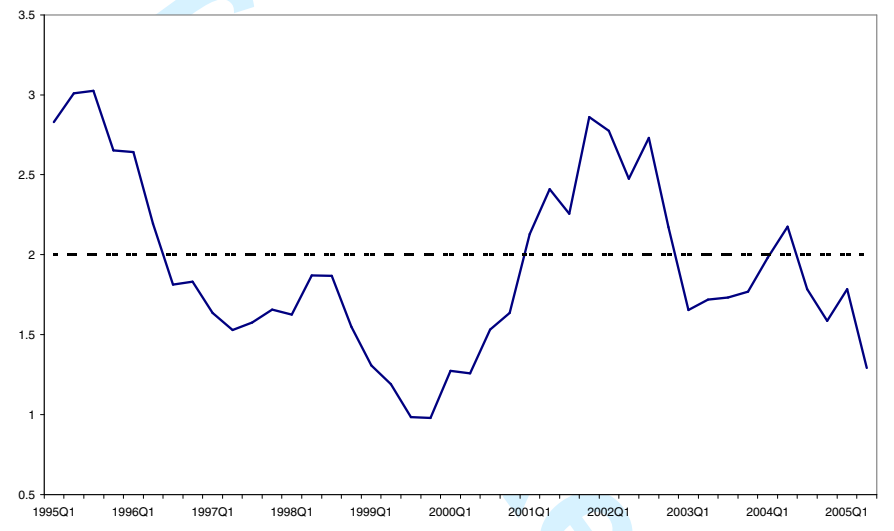

Interest rate changes

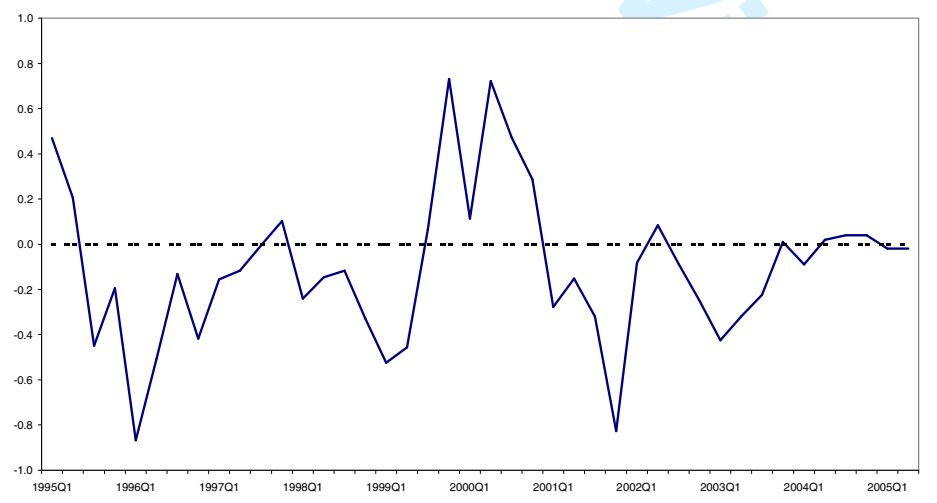

Data sources: Area Wide Model Database AWM12up5, ECB August 2004 (1995:I-2003:IV), ECB Monthly Bulletin (2004:I - 2005:II), and authors' calculations.

Notes: - Output gap is the cycle from an univariate unobserved components model (local linear trend model with autoregressive cycle) of log real GDP 1970:I-2005:II, estimated with the kalman filter with Stock and Watson's (1998) median unbiased estimation of the variance of the trend stochastic drift;

- Inflation $=100 * \ln \left(\mathrm{P}_{\mathrm{t}} / \mathrm{P}_{\mathrm{t}-4}\right)$, where $\mathrm{P}$ is the GDP deflator;

- Interest Rate changes $=i_{\mathrm{t}} i_{\mathrm{t}-1}$, where $i$ is the 3 -month interest rate;

- Dotted lines represent the policy targets; 
Table 1. Tests for Asymmetries in the Preferences of the Monetary Policymaker Euro Area 1995:I - 2005:II

\begin{tabular}{|c|c|c|c|c|c|c|c|c|c|c|c|c|}
\hline & \multicolumn{9}{|c|}{$\begin{array}{c}\text { Parameter Estimates } \\
\text { (P-values) }\end{array}$} & \multicolumn{3}{|c|}{$\begin{array}{c}\text { Test Statistics } \\
\text { (P-values) }\end{array}$} \\
\hline & $\phi$ & $\left.\phi\right|_{\pi \geq 2}$ & $\left.\phi\right|_{\pi<2}$ & $\lambda$ & $\lambda /_{y \geq 0}$ & $\lambda I_{y<0}$ & $\mu$ & $\left.\mu\right|_{\Delta i \geq 0}$ & $\left.\mu\right|_{\Delta i<0}$ & $\left.\phi\right|_{\pi \geq 2}=\left.\phi\right|_{\pi<2}$ & $\lambda I_{y \geq 0}=\lambda I_{y<0}$ & $\left.\mu\right|_{\Delta i \geq 0}=\left.\mu\right|_{\Delta i<0}$ \\
\hline $\begin{array}{l}\text { Asymmetry in Output Gap } \\
\text { Targeting }\end{array}$ & 1.0 & & & & $\begin{array}{l}-0.133 \\
(0.238)\end{array}$ & $\begin{array}{l}-0.131 \\
(0.073)\end{array}$ & $\begin{array}{c}0.002 \\
(0.000)\end{array}$ & & & & $\begin{array}{l}0.001 \\
(0.980)\end{array}$ & \\
\hline $\begin{array}{l}\text { Asymmetry in Inflation } \\
\text { Targeting }\end{array}$ & & $\begin{array}{c}1.164 \\
(0.000) \\
1.366 \\
(0.000)\end{array}$ & $\begin{array}{c}0.836 \\
(0.000) \\
\\
0.634 \\
(0.000)\end{array}$ & $\begin{array}{l}-0.107 \\
(0.158)\end{array}$ & & & $\begin{array}{c}0.002 \\
(0.000) \\
\\
0.002 \\
(0.000)\end{array}$ & & & $\begin{array}{l}0.862 \\
(0.353) \\
10.519 \\
(0.001)\end{array}$ & & \\
\hline $\begin{array}{l}\text { Asymmetry in Interest } \\
\text { Rate Smoothing }\end{array}$ & $\begin{array}{l}1.0 \\
1.0\end{array}$ & & & $\begin{array}{l}-0.124 \\
(0.086)\end{array}$ & & & & $\begin{array}{c}0.002 \\
(0.080) \\
0.003 \\
(0.067)\end{array}$ & $\begin{array}{c}0.002 \\
(0.004) \\
0.002 \\
(0.033)\end{array}$ & & & $\begin{array}{c}0.002 \\
(0.967) \\
0.124 \\
(0.725)\end{array}$ \\
\hline Joint asymmetries & & $\begin{array}{c}1.324 \\
(0.000) \\
1.370 \\
(0.000)\end{array}$ & $\begin{array}{l}0.676 \\
(0.002) \\
0.630 \\
(0.000)\end{array}$ & & $\begin{array}{l}-0.190 \\
(0.139)\end{array}$ & $\begin{array}{l}-0.073 \\
(0.247)\end{array}$ & & $\begin{array}{c}0.002 \\
(0.082) \\
0.003 \\
(0.138)\end{array}$ & $\begin{array}{c}0.002 \\
(0.007) \\
0.002 \\
(0.031)\end{array}$ & $\begin{array}{c}2.227 \\
(0.136) \\
6.635 \\
(0.010)\end{array}$ & $\begin{array}{c}1.227 \\
(0.268)\end{array}$ & $\begin{array}{c}0.043 \\
(0.836) \\
\\
0.223 \\
(0.637)\end{array}$ \\
\hline
\end{tabular}

Notes: - Joint estimation by GMM of system (1) and equation (6) with the appropriate restrictions, with $\pi^{*}=2$ and $\delta=0.975$ (AS-AD coefficients not shown); - GMM estimation with one-step weighting matrix, fully iterated parameters, HAC variance-covariance matrix, Bartlett kernel, Andrews bandwidth;

- Instruments: constant, $\Delta \pi_{\mathrm{t}-\mathrm{i}}, y_{\mathrm{t}-\mathrm{i}}, i_{\mathrm{t}-\mathrm{i}}, \mathrm{I} \pi_{\mathrm{t}-\mathrm{i}}, \mathrm{i}=2,3,4$;

- The test statistics in the last three columns are Wald statistics for the indicated null hypothesis. 


\section{Table 2. Macroeconomic Structure and Asymmetric vs Symmetric Policymaker's Preferences Euro Area 1995: I - 2005:II}

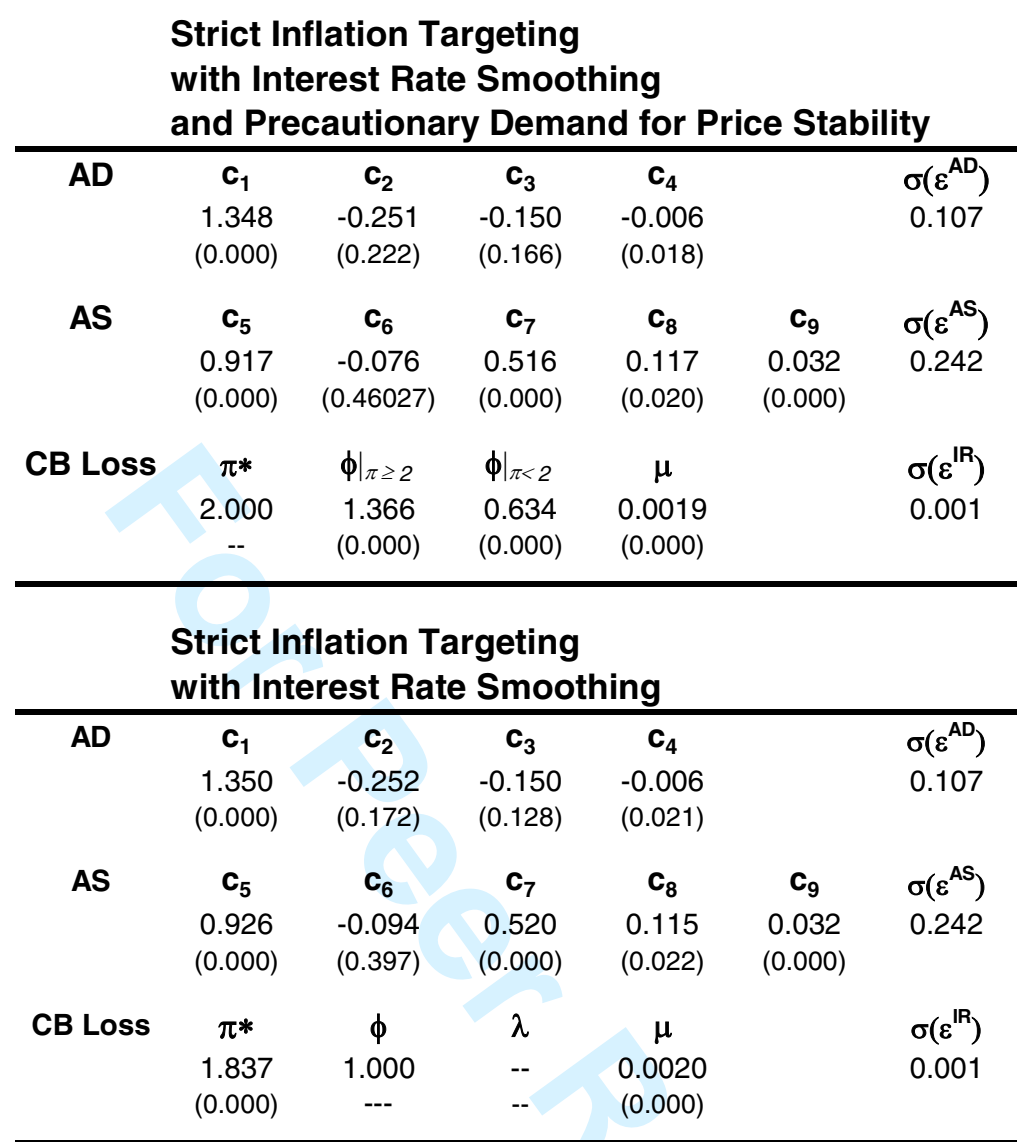

Notes: - Upper panel: joint estimation by GMM of system (1) and equation (6) with $\lambda=0, \mu$ constant, $\pi^{*}=2$ and $\delta=0.975$;

- Lower panel: joint estimation by GMM of system (1) and equation (6) with $\lambda=0, \phi$ and $\mu$ constant and $\delta=0.975$;

- GMM estimation with one-step weighting matrix, fully iterated parameters, HAC variancecovariance matrix, Bartlett kernel, Andrews bandwidth;

- Instruments: constant, $\Delta \pi_{\mathrm{t}-\mathrm{i}}, y_{\mathrm{t}-\mathrm{i}}, i_{\mathrm{t}-\mathrm{i}}, \mathrm{I} \pi_{\mathrm{t}-\mathrm{i}}, \mathrm{i}=2,3,4$;

- P-values in parenthesis. 


\section{Table 3. Sensitivity to Beginning Date of the Notional Monetary Policy Regime in the Euro Area}

\begin{tabular}{|c|c|c|c|c|c|c|c|}
\hline & \multicolumn{5}{|c|}{$\begin{array}{c}\begin{array}{c}\text { Parameter Estimates } \\
\text { (P-values) }\end{array} \\
\end{array}$} & \multicolumn{2}{|c|}{$\begin{array}{c}\text { Test Statistics } \\
\text { (P-values) } \\
\end{array}$} \\
\hline & $\left.\phi\right|_{\pi \geq 2}$ & $\left.\phi\right|_{\pi<2}$ & $\mu$ & $\left.\mu\right|_{\Delta i \geq 0}$ & $\mu \mathrm{|}_{\Delta i<0}$ & $\left.\phi\right|_{\pi \geq 2}=\left.\phi\right|_{\pi<2}$ & $\mu /_{\Delta i \geq 0}=\mu /_{\Delta i<0}$ \\
\hline \multicolumn{8}{|l|}{$\begin{array}{l}\text { Asymmetry in Inflation } \\
\text { Targeting }\end{array}$} \\
\hline 1996:I - 2005:II & $\begin{array}{l}1.344 \\
(0.000)\end{array}$ & $\begin{array}{l}0.656 \\
(0.000)\end{array}$ & $\begin{array}{l}0.001 \\
(0.004)\end{array}$ & & & $\begin{array}{l}6.588 \\
(0.010)\end{array}$ & \\
\hline 1997:I - 2005:II & $\begin{array}{l}1.337 \\
(0.000)\end{array}$ & $\begin{array}{l}0.663 \\
(0.000)\end{array}$ & $\begin{array}{l}0.000 \\
(0.107)\end{array}$ & & & $\begin{array}{l}2.947 \\
(0.086)\end{array}$ & \\
\hline 1998:I - 2005:II & $\begin{array}{l}1.379 \\
(0.000)\end{array}$ & $\begin{array}{l}0.621 \\
(0.000)\end{array}$ & $\begin{array}{l}0.001 \\
(0.008)\end{array}$ & & & $\begin{array}{l}9.043 \\
(0.003)\end{array}$ & \\
\hline \multicolumn{8}{|c|}{$\begin{array}{l}\text { Asymmetry in Inflation } \\
\text { Targeting and in } \\
\text { Interest Rate Smoothing }\end{array}$} \\
\hline 1996:I - 2005:II & $\begin{array}{l}1.411 \\
(0.000)\end{array}$ & $\begin{array}{l}0.589 \\
(0.000)\end{array}$ & & $\begin{array}{l}0.002 \\
(0.022)\end{array}$ & $\begin{array}{l}0.001 \\
(0.056)\end{array}$ & $\begin{array}{l}7.444 \\
(0.006)\end{array}$ & $\begin{array}{l}1.640 \\
(0.200)\end{array}$ \\
\hline 1997:I - 2005:II & $\begin{array}{l}1.402 \\
(0.000)\end{array}$ & $\begin{array}{l}0.598 \\
(0.006)\end{array}$ & & $\begin{array}{l}0.000 \\
(0.112)\end{array}$ & $\begin{array}{l}0.000 \\
(0.411)\end{array}$ & $\begin{array}{l}3.459 \\
(0.063)\end{array}$ & $\begin{array}{l}0.548 \\
(0.459)\end{array}$ \\
\hline 1998:I - 2005:II & $\begin{array}{l}1.413 \\
(0.000)\end{array}$ & $\begin{array}{l}0.587 \\
(0.000)\end{array}$ & & $\begin{array}{l}0.001 \\
(0.014)\end{array}$ & $\begin{array}{l}0.000 \\
(0.293)\end{array}$ & $\begin{array}{l}9.492 \\
(0.002)\end{array}$ & $\begin{array}{l}1.028 \\
(0.311)\end{array}$ \\
\hline
\end{tabular}

Notes: - Joint estimation by GMM of system (1) and equation (6) with the appropriate restrictions, with $\pi^{*}=2$ and $\delta=0.975$ (AS-AD coefficients not shown);

- GMM estimation with one-step weighting matrix, fully iterated parameters, HAC variancecovariance matrix, Bartlett kernel, Andrews bandwidth;

- Instruments: constant, $\Delta \pi_{\mathrm{t}-\mathrm{i}}, y_{\mathrm{t}-\mathrm{i}}, i_{\mathrm{t}-\mathrm{i}}, \mathrm{I} \pi_{\mathrm{t}-\mathrm{i}}, \mathrm{i}=2,3,4$;

- The test statistics in the last two columns are Wald statistics (and p-values) for the indicated null hypothesis. 
Table 4. Sensitivity to Longer Horizons in the Euler equation Euro Area 1995:I - 2005:II

\begin{tabular}{|c|c|c|c|c|c|c|c|}
\hline & \multicolumn{5}{|c|}{$\begin{array}{c}\text { Parameter Estimates } \\
\text { (P-values) }\end{array}$} & \multicolumn{2}{|c|}{$\begin{array}{c}\text { Test Statistics } \\
\text { (P-values) }\end{array}$} \\
\hline & $\left.\phi\right|_{\pi \geq 2}$ & $\left.\phi\right|_{\pi<2}$ & $\mu$ & $\left.\mu\right|_{\Delta i \geq 0}$ & $\left.\mu\right|_{\Delta i<0}$ & $\left.\phi\right|_{\pi \geq 2}=\phi I_{\pi<2}$ & $\left.\boldsymbol{\mu}\right|_{\Delta i \geq 0}=\boldsymbol{\mu} /_{\Delta i<0}$ \\
\hline \multicolumn{8}{|c|}{ Asymmetry in Inflation } \\
\hline$\tau=5$ & $\begin{array}{l}1.420 \\
(0.000)\end{array}$ & $\begin{array}{l}0.580 \\
(0.000)\end{array}$ & $\begin{array}{l}0.003 \\
(0.001)\end{array}$ & & & $\begin{array}{l}14.951 \\
(0.000)\end{array}$ & \\
\hline$\tau=6$ & $\begin{array}{l}1.512 \\
(0.000)\end{array}$ & $\begin{array}{c}0.488 \\
(0.010)\end{array}$ & $\begin{array}{l}0.001 \\
(0.105)\end{array}$ & & & $\begin{array}{l}7.508 \\
(0.006)\end{array}$ & \\
\hline \multicolumn{8}{|c|}{$\begin{array}{l}\text { Asymmetry in Inflation } \\
\text { Targeting and in } \\
\text { Interest Rate Smoothing }\end{array}$} \\
\hline$\tau=5$ & $\begin{array}{r}1.439 \\
(0.000)\end{array}$ & $\begin{array}{l}0.561 \\
(0.000)\end{array}$ & & $\begin{array}{l}0.005 \\
(0.048)\end{array}$ & $\begin{array}{c}0.002 \\
(0.046)\end{array}$ & $\begin{array}{l}10.272 \\
(0.001)\end{array}$ & $\begin{array}{l}0.754 \\
(0.385)\end{array}$ \\
\hline$\tau=6$ & $\begin{array}{l}1.512 \\
(0.000)\end{array}$ & $\begin{array}{c}0.488 \\
(0.030)\end{array}$ & & $\begin{array}{c}0.002 \\
(0.463)\end{array}$ & $\begin{array}{l}0.001 \\
(0.522)\end{array}$ & $\begin{array}{l}5.166 \\
(0.023)\end{array}$ & $\begin{array}{l}0.158 \\
(0.692)\end{array}$ \\
\hline
\end{tabular}

Notes: - See notes to table 3. 
Table 5. Sensitivity to Policymakers' Loss Function without Interest Rate Smoothing Euro Area 1995:I - 2005:II

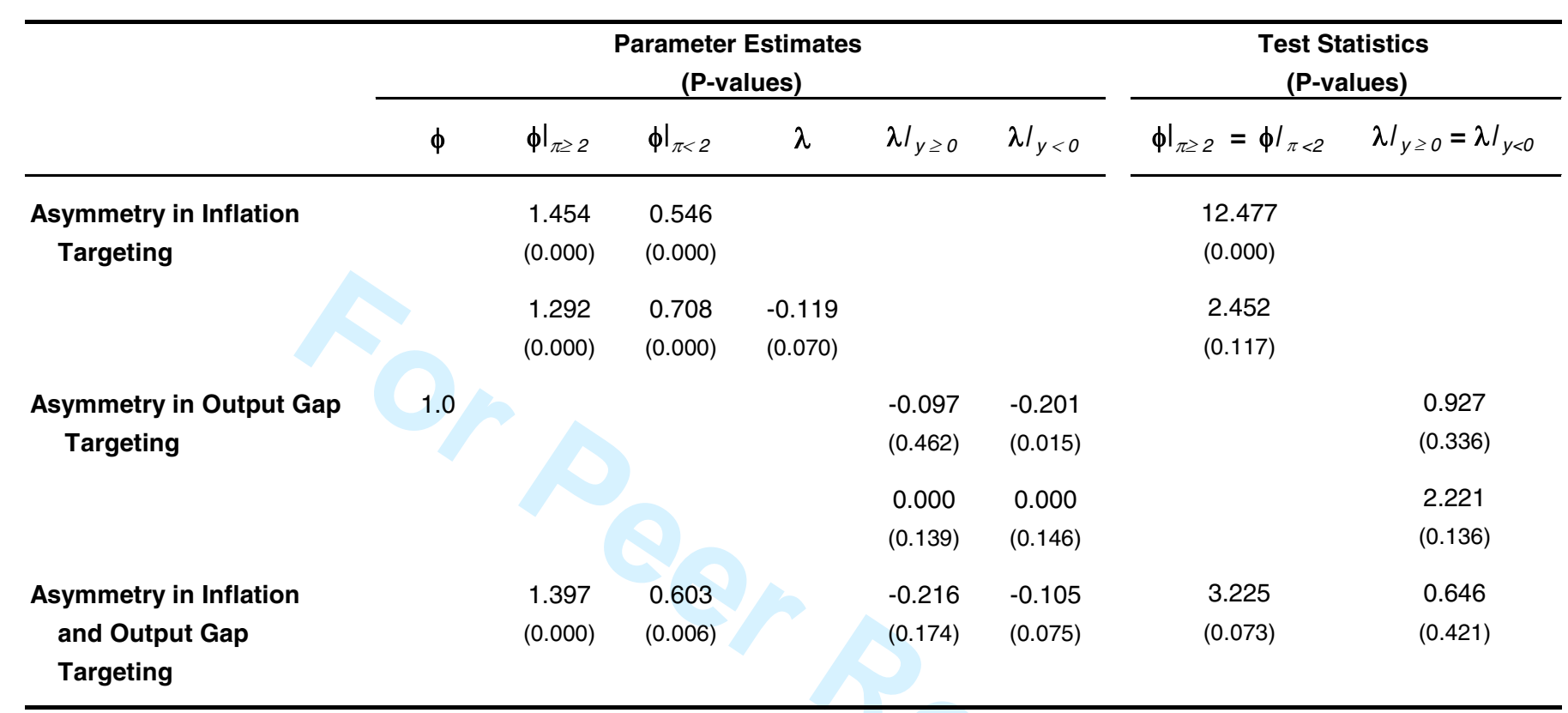

Notes: - See notes to table 3. 
Table 6. Sensitivity to Hodrick-Prescott filter Output Gap Euro Area 1995:I - 2005:II

\begin{tabular}{|c|c|c|c|c|c|c|c|c|c|c|c|c|}
\hline & \multicolumn{9}{|c|}{$\begin{array}{c}\text { Parameter Estimates } \\
\text { (P-values) } \\
\end{array}$} & \multicolumn{3}{|c|}{$\begin{array}{c}\text { Test Statistics } \\
\text { (P-values) }\end{array}$} \\
\hline & $\phi$ & $\left.\phi\right|_{\pi \geq 2}$ & $\left.\phi\right|_{\pi<2}$ & $\lambda$ & $\lambda /_{y \geq 0}$ & $\lambda I_{y<0}$ & $\mu$ & $\left.\mu\right|_{\Delta i \geq 0}$ & $\left.\mu\right|_{\Delta i<0}$ & $\left.\phi\right|_{\pi \geq 2}=\left.\phi\right|_{\pi<2}$ & $\lambda I_{y \geq 0}=\lambda /_{y<0}$ & $\left.\mu\right|_{\Delta i \geq 0}=\left.\mu\right|_{\Delta i<0}$ \\
\hline $\begin{array}{l}\text { Asymmetry in Output Gap } \\
\text { Targeting }\end{array}$ & 1.0 & & & & $\begin{array}{l}0.005 \\
(0.426)\end{array}$ & $\begin{array}{l}-0.028 \\
(0.199)\end{array}$ & $\begin{array}{c}0.001 \\
(0.000)\end{array}$ & & & & $\begin{array}{c}1.847 \\
(0.174)\end{array}$ & \\
\hline $\begin{array}{l}\text { Asymmetry in Inflation } \\
\text { Targeting }\end{array}$ & & $\begin{array}{c}1.430 \\
(0.000) \\
1.463 \\
(0.000)\end{array}$ & $\begin{array}{c}0.570 \\
(0.000) \\
\\
0.537 \\
(0.000)\end{array}$ & $\begin{array}{r}-0.012 \\
(0.211)\end{array}$ & & & $\begin{array}{c}0.001 \\
(0.000) \\
0.001 \\
(0.002)\end{array}$ & & & $\begin{array}{l}19.237 \\
(0.000) \\
24.862 \\
(0.000)\end{array}$ & & \\
\hline $\begin{array}{l}\text { Asymmetry in Interest } \\
\text { Rate Smoothing }\end{array}$ & $\begin{array}{l}1.0 \\
1.0\end{array}$ & & & $\begin{array}{l}-0.007 \\
(0.5073)\end{array}$ & & & & $\begin{array}{c}0.001 \\
(0.3866) \\
0.001 \\
(0.231)\end{array}$ & $\begin{array}{l}0.001 \\
(0.005) \\
0.001 \\
(0.056)\end{array}$ & & & $\begin{array}{c}0.205 \\
(0.650) \\
0.011 \\
(0.915)\end{array}$ \\
\hline Joint asymmetries & & $\begin{array}{c}1.353 \\
(0.000) \\
1.493 \\
(0.000)\end{array}$ & $\begin{array}{l}0.647 \\
(0.000) \\
\\
0.507 \\
(0.000)\end{array}$ & & $\begin{array}{l}-0.004 \\
(0.540)\end{array}$ & $\begin{array}{l}-0.015 \\
(0.242)\end{array}$ & & $\begin{array}{l}0.002 \\
(0.004) \\
\\
0.002 \\
(0.013)\end{array}$ & $\begin{array}{l}0.001 \\
(0.006) \\
0.001 \\
(0.024)\end{array}$ & $\begin{array}{l}5.180 \\
(0.023) \\
27.260 \\
(0.000)\end{array}$ & $\begin{array}{l}0.829 \\
(0.363)\end{array}$ & $\begin{array}{l}2.181 \\
(0.140) \\
\\
2.022 \\
(0.155)\end{array}$ \\
\hline
\end{tabular}

Notes: - See notes to table 3. 
Table 7. Sensitivity to alternative lags in AS-AD structure Euro Area 1995:I - 2005:II

\begin{tabular}{|c|c|c|c|c|c|c|}
\hline \multirow{2}{*}{$\begin{array}{l}\text { AS-AD } \\
\text { structure }\end{array}$} & \multirow{2}{*}{$\begin{array}{l}\text { CB Loss } \\
\text { Function }\end{array}$} & \multicolumn{2}{|c|}{ Estimates } & \multicolumn{3}{|c|}{ P-values of Wald Statistics } \\
\hline & & $\left.\phi\right|_{\pi \geq 2}$ & $\left.\phi\right|_{\pi<2}$ & $\left.\phi\right|_{\pi \geq 2}=\left.\phi\right|_{\pi<2}$ & $\lambda I_{y \geq 0}=\lambda I_{y<0}$ & $\mu I_{\Delta i \geq 0}=\mu I_{\Delta i<0}$ \\
\hline \multirow[t]{4}{*}{$A D(3)-A S(1)$} & (i) & 1.446 & 0.554 & 0.000 & & \\
\hline & (ii) & 1.458 & 0.542 & 0.003 & & 0.304 \\
\hline & (iii) & 1.545 & 0.455 & 0.023 & 0.112 & \\
\hline & (iv) & 1.513 & 0.487 & 0.038 & 0.122 & 0.936 \\
\hline \multirow[t]{4}{*}{$A D(1)-A S(0)$} & (i) & 1.388 & 0.612 & 0.000 & & \\
\hline & (ii) & 1.388 & 0.612 & 0.001 & & 0.865 \\
\hline & (iii) & 1.409 & 0.591 & 0.212 & 0.491 & \\
\hline & (iv) & 1.413 & 0.587 & 0.198 & 0.489 & 0.956 \\
\hline \multirow[t]{4}{*}{$A D(1)-A S(1)$} & (i) & 1.391 & 0.609 & 0.000 & & \\
\hline & (ii) & 1.404 & 0.596 & 0.001 & & 0.445 \\
\hline & (iii) & 1.635 & 0.365 & 0.014 & 0.140 & \\
\hline & (iv) & 1.633 & 0.367 & 0.013 & 0.146 & 0.841 \\
\hline \multirow[t]{4}{*}{$A D(2)-A S(0)$} & (i) & 1.322 & 0.678 & 0.003 & & \\
\hline & (ii) & 1.325 & 0.675 & 0.012 & & 0.705 \\
\hline & (iii) & 1.404 & 0.596 & 0.148 & 0.294 & \\
\hline & (iv) & 1.396 & 0.604 & 0.130 & 0.300 & 0.896 \\
\hline \multirow[t]{4}{*}{$A D(2)-A S(1)$} & (i) & 1.417 & 0.583 & 0.000 & & \\
\hline & (ii) & 1.437 & 0.563 & 0.001 & & 0.380 \\
\hline & (iii) & 1.413 & 0.587 & 0.095 & 0.184 & \\
\hline & (iv) & 1.413 & 0.587 & 0.087 & 0.195 & 0.804 \\
\hline \multirow[t]{4}{*}{$A D(4)-A S(0)$} & (i) & 1.447 & 0.553 & 0.000 & & \\
\hline & (ii) & 1.480 & 0.520 & 0.001 & & 0.314 \\
\hline & (iii) & 1.476 & 0.524 & 0.068 & 0.126 & \\
\hline & (iv) & 1.449 & 0.551 & 0.079 & 0.139 & 0.978 \\
\hline \multirow[t]{4}{*}{$A D(4)-A S(1)$} & (i) & 1.661 & 0.339 & 0.008 & & \\
\hline & (ii) & 1.701 & 0.299 & 0.008 & & 0.057 \\
\hline & (iii) & 1.718 & 0.282 & 0.000 & 0.119 & \\
\hline & (iv) & 1.675 & 0.325 & 0.001 & 0.153 & 0.809 \\
\hline$A D(1,2,3,4)$ & (i) & 1.479 & 0.521 & 0.000 & & \\
\hline \multirow[t]{3}{*}{$\mathrm{AS}(1)$} & (ii) & 1.508 & 0.492 & 0.001 & & 0.300 \\
\hline & (iii) & 1.367 & 0.633 & 0.022 & 0.299 & \\
\hline & (iv) & 1.393 & 0.607 & 0.010 & 0.336 & 0.228 \\
\hline
\end{tabular}

Notes: - Joint estimation by GMM of the indicated AS-AD system and the corresponding Euler equation, with appropriate restrictions, for alternative Loss asymmetry tests, given $\pi^{*}=2$ and $\delta=0.975$;

- The parenthesis in the first column (AS-AD), indicate the lag of the explanatory variable, ie $\mathrm{AD}(2)$ means that the $\mathrm{AD}$ includes a second lag of the real interest rate, $\mathrm{AS}(1)$ means that the $\mathrm{AS}$ has a one-quarter lagged output gap;

- The loss function specifications indicated in the second column correspond to tests of the following asymmetries: (i) asymmetry in inflation targeting; (ii) asymmetry in inflation targeting and in interest rate smoothing (iii) asymmetry in inflation targeting and in output gap targeting; (iv) asymmetry in inflation targeting, in output gap targeting and in interest rate smoothing; (i) and (ii) are regimes of strict inflation targeting with interest rate smoothing, while (iii) and (iv) are regimes of flexible inflation targeting with interest rate smoothing;

- GMM estimation with one-step weighting matrix, fully iterated parameters, HAC variancecovariance matrix, Bartlett kernel, Andrews bandwidth; Instruments: constant, $\Delta \pi_{\mathrm{t}-\mathrm{i}}, y_{\mathrm{t}-\mathrm{i}}, i_{\mathrm{t}-\mathrm{i}}, \mathrm{I} \pi_{\mathrm{t}-\mathrm{i}}$ $\mathrm{i}=2,3,4$; 